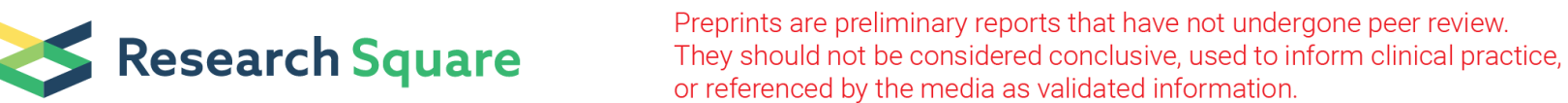

\section{Determinant of Stroke among Adult Patients with Hypertension in Ayder Comprehensive Specialized Hospital, Tigray, Ethiopia, 2018: A Case Control Study}

Haftea Hagos mekonen ( $\nabla$ hafteahagos2@gmail.com )

Adigrat University

Mulugeta Molla Brhanu

St. Paul's Hospital, Millennium Medical College

Tilahun Belete Mossie

Bahirdar University

Hagos Tsegabrhan Gebreslassie

Mekelle University

Research article

Keywords: Stroke, Hypertension, determinant, Mekelle, Ethiopia

Posted Date: June 6th, 2019

DOl: https://doi.org/10.21203/rs.2.10121/v1

License: (c) (1) This work is licensed under a Creative Commons Attribution 4.0 International License.

Read Full License 


\section{Abstract}

Background: Stroke is a chronic non-communicable disease results from infraction or spontaneous hemorrhage in the brain. The burden of stroke is increasing in alarming rate globally. In 2013 there were 6.5 million stroke deaths, 113 million disability-adjusted life years due to stroke from this, $75.2 \%$ of all stroke mortality and $81.0 \%$ of stroke-related disability-adjusted life years are from the developing countries. In Ethiopia, 7\% of total deaths are attributed by stroke. This study aims to assess the determinants of stroke among patients with hypertension in Ayder Comprehensive Specialized Hospital, Mekelle, Tigray, Ethiopia, in 2018. Methods: Hospital-based case-control study was conducted from February to April 2018. Cases were adult hypertensive patients with stroke and controls were adult hypertensive patients without stroke. Using a systematic random sampling technique 89 case and 356 controls were included in this study. Record review, physical measurement and interview techniques were used to collect data. Data was entered and analyzed by using SPSS version 23 . Variables with a p-value less than 0.25 in bivariate logistic regression were selected for multivariable logistic regression. The adjusted odds ratio and $95 \%$ confidence interval were used to determine the association. P-value $<0.05$ was used to declare statistical significance in multivariable analysis. Result: The mean age of cases were $56.3 y e a r s(S D \pm 13.53 y e a r s)$ and 51.9 years ( $S D \pm 12.67$ years) for controls. Majority $59(66.3 \%)$ of the case and around one third $106(30 \%)$ of controls were non-adherent to medication. Lost to follow up $(A O R=2.474,95 \% \mathrm{Cl}: 1.368-4.929)$, alcohol drinking ( $A O R=2.440,95 \% \mathrm{Cl}: 1.291-4.613)$, use of salty diet (AOR=3.249, 95\% Cl: (1.544-6.837), medication non-adherence (AOR=3.967, 95\% Cl: 2.256-6.973), uncontrolled systolic blood pressure, (AOR=3.196, 95\% Cl: 1.60-6.382), uncontrolled diastolic blood pressure (AOR=2.204, 95\% Cl: 1.130-4.297) and high cholesterol level(AOR=2.413, 95\%Cl: 1.319-4.414) were found to be significant determinants. Conclusion: Alcohol consumption, lost to follow up, salty diet, high cholesterol level and uncontrolled systolic and diastolic blood pressure were significantly associated with stroke so, health education on lifestyle practices and hypertension-related complications in each follow-up visit through health professionals are very essential to avert the problem. Keywords: Stroke, Hypertension, determinant, Mekelle, Ethiopia

\section{Background}

Stroke is a chronic non-communicable disease causes sudden global focal neurological deficit resulting from infraction or spontaneous hemorrhage in the brain[1]. The incidence of stroke on the past four decades (1970-2010) showed, 100\% increases in low and middle-income countries but it decreases by $42 \%$ in developed countries[2]. In 2013, there were 6.5 million stroke deaths, 113 million disabilityadjusted life years due to stroke. Of all, $75.2 \%$ of stroke mortality and $81.0 \%$ of stroke-related disabilityadjusted life years were in developing countries[3].

In addition to the health consequence cardiovascular disease and stroke has a major impact in economic development. World Economic Forum and WHO forcasts above 7 trillion American dollar over the period 2011-2025 in low and middle-income countries (LMIC)[4]. 
The American heart association plans to reduce disease and deaths from stroke by 20 percent in 2020 by focusing on seven key health factors and behaviors that decreases risk for stroke, those are not-smoking, physical activity, healthy diet, body weight, and control of cholesterol, blood pressure, and blood sugar[5].

Different studies in different parts of the world stated the common determinant of stroke: age, sex, and smoking, low physical exercise, obesity, alcohol, anti-hypertensive medication non-adherence, uncontrolled blood pressure, being diabetic, and cholesterol level (10)[4, 6-9] But the above factors are different across the studies.

In $2015 / 16-2019 / 20$ the Ethiopian health sector development program projects to decrease by $12.5 \%$ premature mortality from NCDs[10]. In Ethiopia, currently stroke is one of the greatest public health problem, accounts $7 \%$ of total deaths[11]. Study in Mekelle, Ethiopia showed that stroke was the third common cause of medical intensive care unit admission (15.2\%) and the first cause of death which accounts $17 \%$ of all death in medical intensive care unit[12]. Similarly hypertension is responsible for $66.2 \%$ of all strokes admission and $38 \%$ of all stroke were on anti-hypertensive treatment[13].

In Ethiopia although, admission of stroke patients to the hospitals due to hypertension is increased from time to time, there are limited findings which aim to explore those determinants.

Therefore, this study aims to assess the determinants of stroke among hypertensive patients at Ayder Comprehensive Specialized Hospital, Mekelle, Ethiopia, 2018.

\section{Methods}

\section{Study setting}

Ayder Comprehensive Specialized Hospital is found in Mekelle, Tigray regional state, Ethiopia. Mekelle is found at $783 \mathrm{Km}$ north of Addis Ababa. Mekelle has total population 586,897. Mekelle city has nine governmental health centers, one referral Hospital and one military Hospital and two general hospitals. Ayder Comprehensive Specialized Hospital begins its referral and non-referral services in 2008 to the 9 million populations in its catchment areas of the Tigray, Afar and parts of the Amhara regional states in Ethiopia[14].

Ayder Comprehensive Specialized Hospital has capacity of about 500 beds in four major departments and other specialty units. Patient flow of ACSH is above170, 000 per year. The hospital provides hypertensive service in cardiac unit and stroke service in neurology unit. Medical ward, medical ICU, cardiac unit and diabetic unit were the study units[14].

\section{Study design and period}

A case-control study was conducted in Ayder comprehensive specialized Hospital, Tigray from February to April 2018. 


\section{Population and sampling}

Cases were all sampled adult hypertensive patients with stroke diagnosed by the neurologist (consultant internist) or confirmed by brain imaging (CT-scan) or MRI. Controls were all sampled adult hypertensive patients without clinical evidence of stroke and without a history of stroke at ACSH during the data collection period. Cases with less than three follow-ups for hypertension treatment before first stroke occurrence and controls with less than three follow-ups for hypertension treatment were excluded. Pregnant mothers were also excluded from both cases and controls. The sample size was calculated using Epi Info version 7 statistical software using the following assumptions: a proportion of $10.7 \%$ and $24.1 \%$ of greater alcohol consumption was considered for controls and cases respectively[7] at $95 \% \mathrm{Cl}$, $80 \%$ power. The case to control ratio was 1:4. Using those information 81 cases and 324 controls were selected but after adding 10\% non-response rate the total sample becomes 445 of which 89 were cases and 356 were controls. Finally eligible cases and controls recruited using systematic sampling technique.

\section{Data Collection Procedure}

Record review of hypertensive and stroke patients was conducted to identify cases and controls. Information on socio-demographic data and behavioral risk factors for stroke was obtained from the patient or close relative (for unconscious cases) by interview.

Medical history like clinical duration of hypertension, type of stroke, the presence of stroke, and complication other than stroke was taken from the patient record. Height, weight, blood pressure, total cholesterol level and fasting blood sugar were taken during data collection.

During data collection data collector measures weight, height, blood pressure, as follows. Weight was measured in light closing and without shoes by calibrated UNICEF Seca digital weighing scale. Stadiometer in centimeter in erect position at a precision of $0.1 \mathrm{~cm}$ without shoes was used to measure height. Mercury sphygmomanometer was used to measure blood pressure average of two measurements 5 minutes apart was recorded for those who we take BP during the data collection.

\section{Assessment and definition of variables}

Outcome variable: Stroke

\section{Independent variables}

Scio demographic included: age, sex, marital status, occupation, residency and educational status.

Behavioral factors included: Physical exercise, Smoking, alcohol, frequency of fellow up, salty diet, fatty food use, loss to fellow up, medication adherence

physical exercise physically active- if patients make regular physical activities 30 minutes and above, 5 days and above per week physically inactive- if patient is make physical exercise less than 30 minutes per week or less than 5 days per week[15]. , Medication adherence was assessed using Morisky 
medication adherence score to anti-hypertensive medications having eight questions each with yes $=0$ and $\mathrm{No}=\mathrm{I}$, adherent if they score 7-8 and non-adherent if they score $<=6[16]$.

Alcohol drinker- a person who drinks 10.5 unites of alcohol and above per week[15].

Physical measurements and clinical factors: Fasting blood glucose (FBG), cholesterol level, blood pressure control, body mass index (BMI) and comorbidities. Normal FBG $<126 \mathrm{mg} / \mathrm{dl}$, raised FBG $>=126$ $\mathrm{mg} / \mathrm{dl}[7]$.

Cholesterol level: normal if less than 200 and high cholesterol level 200 and above, BMl: underweight(less than 18.5), normal (18.5-24.9), over weight (25-29.9) and obese (30 and above). Systolic blood pressure: controlled $(<140)$ and uncontrolled $(>=140)$, diastolic blood pressure: controlled $(<90)$ and uncontrolled(>=90)[17]. Comorbidities: yes if patient has any known medical disease.

\section{Data analysis and management}

Data were cleaned, coded, entered and analyzed using SPSS version 23. Summary statistics: frequencies tables and graphs were used to present for categorical variables and mean, median for continuous variables in both cases and controls.

First bivariate logistic regression was done to assess the association between each independent variable and the dependent variable. Variable with a P-value $<0.25$ significance level in bivariate logistic regression was taken to multivariable logistic regression. Finally multivariable logistic regression was used to assess the association between independent variables with the dependent variable and to control confounding variables. Adjusted odds ratio and P-value $<0.05$ and with $95 \% \mathrm{Cl}$ was used to declare statistical significance.

\section{Results}

\section{Socio-demographic characteristics:}

All 445 selected participants (89 cases and 356 controls) were participated in the study and the response rate was $100 \%$. The mean age of cases was 56.3years ( $S D \pm 13.53$ years) and 51.9 years (SD \pm 12.67 years) for controls.

The majority of subjects were married; $64 \%$ in cases and $66 \%$ in controls. Thirty (33.3\%) of the cases and $117(32.9 \%)$ of controls were self-employee (Table 1).

\section{Behavioral factors of the respondents}

Out of 89 cases and 356 controls $32(36 \%)$ of cases and $49(13.8 \%)$ controls were current alcohol drinkers. Twenty two $(24.7 \%)$ cases and $28(7.9 \%)$ of controls of were not reduce salt in their diet. In this study $66.3 \%$ of the cases and $29.8 \%$ of controls were non-adherent to medication. Sixty three $(70.8 \%)$ and 
245(68.8\%) controls were not on regular exercise.36\% of cases and 12.9 of controls had lost to follow up. Fifty two (58.4\%) of cases and $215(60.4 \%)$ of controls had every two months regular follow up (Table 2 ).

\section{Biological, physical measurements and Clinical Characteristics of the respondents}

Among the study participants, $13(14.6 \%)$ of cases and $60(16.9 \%)$ of controls were overweight. The clinical characteristics of patients showed that $5(5.6 \% \%)$ of cases and $25(7 \%)$ of controls of the participants had a family history of stroke (Table 3 ).

The mean of the clinical duration of hypertension was $4.65 \pm 3.3$ years for cases and $3.94 \pm 3.18$ years for controls. The mean of total cholesterol was $198 \pm 34$ among cases and $182 \pm 27$ for controls. The mean systolic blood pressure was $150 \pm 14$ in case and $145 \pm 17$ in controls. The mean diastolic blood pressure was $92 \pm 7$ in case and $90 \pm 9$ in controls.

\section{Types of stroke and method used to diagnosis}

The type of stroke (ischemic or hemorrhagic) and the tool by what they identified could be diagnosed was from the patients chart. Out of 89 cases 29 were ischemic stroke cases and 60 were hemorrhagic stroke. From all stroke $80 \%$ were diagnosed by CT scan, $4.5 \%$ by MRI and $15.7 \%$ clinically.

\section{Bivariate and multivariable logistic regression for factors associated with stroke among hypertensive patients}

The bivariate analysis result reveals that age, lost to follow up, alcohol drinkers after he/she know their hypertensive status, use of salty diet, use of fatty diet; medication non non-adherence, high cholesterol level, and uncontrolled systolic and diastolic blood pressure were found be significant predictors of stroke (annex 1).

Multivariable logistic regression lost to follow up ( $\mathrm{AOR}=2.474,95 \% \mathrm{Cl}$ : 1.368-4.929), alcohol drinkers after he/she know their hypertensive status(AOR=2.440,95\% Cl: 1.291-4.613), use of salty $\operatorname{diet}(\mathrm{AOR}=3.249$, 95\%Cl: 1.544-6.837), medication non-adherence(AOR=3.967, 95\%Cl: 2.256-6.973), high cholesterol level(AOR=2.413, 95\%Cl: 1.319-4.414), uncontrolled systolic(AOR=3.196, 95\%Cl: 1.60-6.382) and diastolic blood pressure(AOR=2.204, 95\% Cl: 1.130-4.297) were found be significant predictors of stroke(Table 4).

\section{Discussion}

This case-control study aimed to identify determinant of stroke among hypertensive patients in Ayder comprehensive specialized hospital, Tigray, north Ethiopia. Lost to follow up, current alcohol drinking, eating salty foods, medication non- adherence, high cholesterol level, uncontrolled systolic and diastolic blood pressure were determinants of stroke.

In this study, patients who had history of lost to follow up were 2.5 times more likely to be at high risk for stroke than their counterparts (AOR=2.474, 95\% Cl: 1.368-4.929). This finding is in agreement with a 
study conducted in Gaza Strip, Germany[18]. This similarity might be due to missing their routine medications and life style modification counseling leads to uncontrolled hypertension.

Hypertensive patients, who were alcohol drinkers, were 2.44 times more likely to be at high risk for stroke (AOR=2.440,95\%Cl: 1.291-4.613). This finding is in line with a study conducted in Nigeria[7] and in 32 countries (INTERSTROKE)[6]. This similarity might be due to alcohol has direct impact on raising blood pressure.

Hypertensive patients who did not reduce salt in diet were around 3.2 times more likely to be at high risk for stroke (AOR=3.249, 95\% Cl: 1.544-6.837). This is similar with a study done in 32 countries (INTERSTROKE)[6]. It is due to the fact salt have an impact on raising blood pressure on circulation then can cause stroke.

In this study medication none-adhered were 4 times (AOR=3.967, 95\%Cl: 2.256-6.973) more likely to be at high risk for stroke than the medication adherent patient. This finding is in line with a study done in Dhaka, Bangladesh[19]. and Gaza Strip, Germany[18].

Patients with high cholesterol level were 2.4 times (AOR=2.413,95\% Cl: $1.319-4.414)$ more likely to be at high risk for stroke than patients with low cholesterol level. This finding is consistent with a study conducted in Nigeria[7] and Tanzania [20]. low high-density lipoprotein (HDL) $(O R=6.84, P<0.001$.[21] dyslipidemia (odds ratio, $1.52 ; 95 \% \mathrm{Cl}, 1.24$ to 1.87 ) [22] low high-density lipoprotein cholesterol (OR, 1.81; $95 \% \mathrm{Cl}, 1.37-2.40$ )[23] This might due to cholesterol have a direct impact on block blood circulation and can cause stroke. But study Erbil reveals that there was no statistically significant difference between the groups with and without stroke with respect to Cholesterol variation(9)[8]. This might be due to sample size, study design. The major reasons for these contradictions may be inadequate control for potential confounders or lack of data on total and type-specific stroke since different associations may exist between total cholesterol and total stroke and between total cholesterol and type-specific stroke risk.

Result of this study showed that uncontrolled systolic blood pressure is 3.2 times more likely at high risk for the development of stroke(AOR=3.196, 95\% Cl: 1.60-6.382) and uncontrolled diastolic blood pressure were 2.2 times more likely for the development of stroke (AOR=2.204, 95\% Cl: 1.130-4.297) this in lines with a study done in Puget[24](OR, 1.43; 95\% Cl, 1.17-1.75)[23]. This might be related to the fact that uncontrolled blood pressure cause hemorrhage in the brain.

\section{Limitations}

Control subjects were not recruited from general population, so selection bias of control subjects may also have affected the findings of this study. Blood pressure measurements were taken from patient's record review hence no information was available on how BP was measured for the previous two measurements. A case control study design was used which does not allow for temporal relationship to be established. 


\section{Conclusions}

Among hypertensive patients, alcohol consumption, lost to follow up, salty diet, and high cholesterol level, uncontrolled systolic and diastolic blood pressure found to be associated with stroke. Therefore, further intervention and prevention mechanism shall focus on these determinants.

\section{Abbreviations}

ACSH: Ayder Comprehensive Specialized Hospital, AOR: Adjusted Odds Ratio, BMI: Body Mass Index, Cl: Confidence Interval, CT: Computed Topography scan, DM: Diabetes Mellitus, ECSA: Ethiopian Central Statistical Agency, EDHS: Ethiopian Demographic Health Survey, MRI: Magnetic Resonance Imaging, NGO: Non-Governmental Organizations, OPD: Out Patient Department, OR: Odds Ratio, SPSS: Statistical Package for the Social Science, SSA: Sub Saharan Africa, WHO: World Health Organization.

\section{Declarations}

\section{Ethics approval and consent to participate}

Ethical clearance was obtained from Mekelle University, College of health science institutional review board (IRB). Official permission was obtained from ACSH chief executive director and study participants were informed about the purpose of the study. The information was collected after obtaining written informed consent from participant (relatives for patients who were critically ill). The respondents were informed as they have the right to refuse or discontinue participation at any time if unwanted. The information was recorded anonymously and confidentiality and beneficence was assured throughout the study period.

\section{Consent for publication}

Not applicable

\section{Availability of data and material}

English version questionnaires, tables are included in supplementary additional files.

Dataset is available from the corresponding author on reasonable request.

\section{Competing interests}

We declare that there is no competing interests.

\section{Funding}

No funding

\section{Authors' contributions}

$\mathrm{HH}$ conception of research idea, study design, coordinated data collection, made analysis and interpreted findings, and drafted the manuscript. MM, TB, HT contributed in design, 
analysis, interpretation of the findings, and reviewed the manuscript. All authors read and approved the final version of the manuscript.

\section{Acknowledgements}

First of all, I would like to thank data collectors, supervisors for their great effort in acquiring necessary information. I would also like thank you for study participants for their cooperated in providing the necessary information.

\section{References}

1. Brunner, L.S., Brunner \& Suddarth's textbook of medical-surgical nursing. 12 ed. Vol. 1. 2010: Lippincott Williams \& Wilkins.

2. Feigin, V.L., et al., Worldwide stroke incidence and early case fatality reported in 56 population-based studies: a systematic review. The Lancet Neurology, 2009. 8(4): p. 355-369.

3. Feigin, V.L., et al., Update on the global burden of ischemic and hemorrhagic stroke in 1990-2013: The GBD 2013 study. 2015.

4. Silberberg, D., et al., Brain and other nervous system disorders across the lifespan-global challenges and opportunities. Nature, 2015. 527(7578): p. S151.

5. Benjamin, E.J., et al., Heart disease and stroke statistics-2017 update: a report from the American Heart Association. Circulation, 2017. 135(10): p. e146-e603.

6. O'Donnell, M.J., et al., Global and regional effects of potentially modifiable risk factors associated with acute stroke in 32 countries (INTERSTROKE): a case-control study. The Lancet, 2016. 388(10046): p. 761-775.

7. Owolabi, M. and A. Agunloye, Risk factors for stroke among patients with hypertension: A casecontrol study. Journal of the neurological sciences, 2013. 325(1-2): p. 51-56.

8. Ismail, K.H., N.G. Al Tawil, and T.S. Al-Hadithi, Risk Factors for Stroke in Erbil City: A Case-Control Study.

9. Li, C., et al., Blood pressure control and risk of stroke: a population-based prospective cohort study. Stroke, 2005. 36(4): p. 725-730.

10. FDREMH, health sector transformation plan. 2015/16.: Ethiopia.

11. CDC, Centers for disease control and prevention. 2016.: Ethioia.

12. Gidey, K., A. Hailu, and A. Bayray, pattern and outcome of medical intensive care unit admissions to ayder comprehensive specialized hospital in tigray, ethiopia. Ethiopian medical journal, 2017. 56(1).

13. Gebremariam, S.A. and H.S. Yang, Types, risk profiles, and outcomes of stroke patients in a tertiary teaching hospital in northern Ethiopia. eNeurologicalSci, 2016. 3: p. 41-47.

14. Hospita, M.U.A.C.S., I [cited 1.6.2018; Available from: http://www.mu.edu.et/chs/index.php/ayderreferral-hospital. 2015. 
15. FMHACA, Standard Treatment Guidlines for General hospital. ,. 2014: Addis Ababa.

16. Morisky, D.E., et al., Predictive validity of a medication adherence measure in an outpatient setting. The Journal of Clinical Hypertension, 2008. 10(5): p. 348-354.

17. James, P.A., et al., 2014 evidence-based guideline for the management of high blood pressure in adults: report from the panel members appointed to the Eighth Joint National Committee (JNC 8). Jama, 2014. 311(5): p. 507-520.

18. Aljeesh, Y.I., Stroke and non-compliance with the therapeutic regimen among hypertensive men and women in Gaza Strip. Stroke and non-compliance with the therapeutic regimen among hypertensive men and women in Gaza Strip, 2003.

19. Siddiqui, M.R., et al., Socio-demographic Status \& Associated Risk Factors of the Stroke Patient's in a Tertiary Care Hospital of Bangladesh. Anwer Khan Modern Medical College Journal, 2013. 4(2): p. 18-22.

20. Walker, R.W., et al., Stroke risk factors in an incident population in urban and rural Tanzania: a prospective, community-based, case-control study. The Lancet Global Health, 2013. 1(5): p. e282e288.

21. Khodabandehlou, M., et al., Risk factors associated with ischemic stroke: A case-control study. Journal of Biostatistics and Epidemiology, 2016. 2(3): p. 111-117.

22. Mazzaglia, G., et al., Patterns of persistence with antihypertensive medications in newly diagnosed hypertensive patients in Italy: a retrospective cohort study in primary care. Journal of hypertension, 2005. 23(11): p. 2093-2100.

23. Kivioja, R., et al., Risk Factors for Early-Onset Ischemic Stroke: A Case-Control Study. Journal of the American Heart Association, 2018. 7(21): p. e009774.

24. Klungel, $\mathrm{O} . \mathrm{H}$., et al., Control of blood pressure and risk of stroke among pharmacologically treated hypertensive patients. Stroke, 2000. 31(2): p. 420-424.

\section{Tables}

Table 1: Socio demographic characteristics of hypertensive patients who were attending ACSH, Ethiopia $(\mathrm{n}=445), 2018$ 
Variables

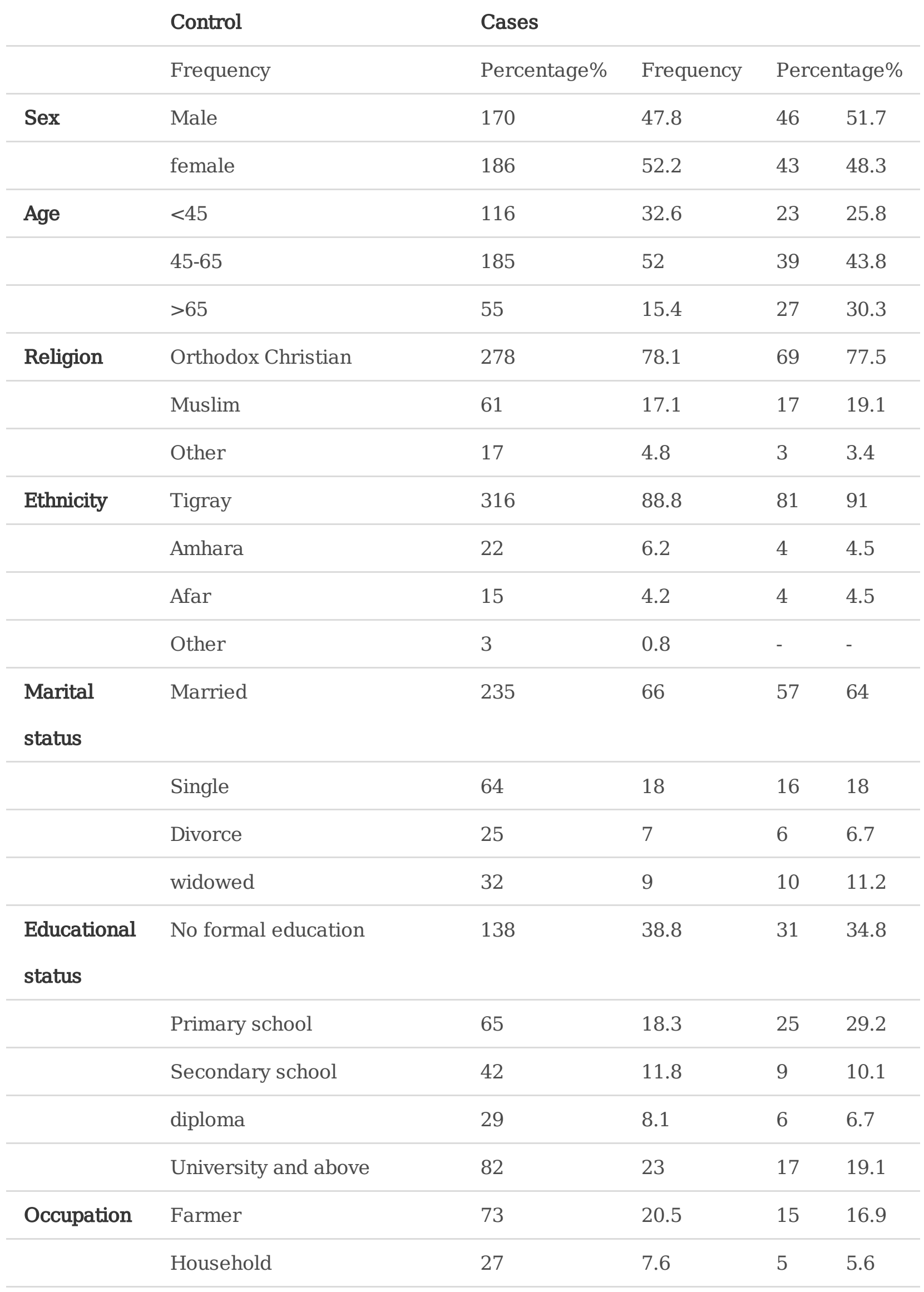




\begin{tabular}{llcccc} 
& Governmental employee & 100 & 28.1 & 20 & 22.5 \\
\hline Non-Governmental employee & 32 & 9 & 15 & 16.9 \\
\hline & Self-employee & 117 & 32.9 & 30 & 33.7 \\
\hline & Other & 7 & 2 & 4 & 4.5 \\
\hline Residency & Rural & 85 & 23.9 & 21 & 24.7 \\
\hline & urban & 271 & 76.1 & 67 & 75.3
\end{tabular}

Table 2: Behavioral determinants of hypertensive patients who were attending ACSH, Ethiopia $(\mathrm{n}=445), 2018$ 
Variables

\begin{tabular}{|c|c|c|c|c|c|}
\hline \multirow[b]{3}{*}{ Have you ever smoke cigarette } & \multirow{3}{*}{$\begin{array}{l}\text { Control } \\
\text { Frequency } \\
\text { Yes }\end{array}$} & \multicolumn{4}{|l|}{ Cases } \\
\hline & & \multirow{2}{*}{$\begin{array}{l}\text { Percentage\% } \\
10\end{array}$} & \multirow{2}{*}{$\begin{array}{l}\text { Frequency } \\
2.8\end{array}$} & \multicolumn{2}{|c|}{ Percentage $\%$} \\
\hline & & & & 2 & 2.2 \\
\hline & No & 346 & 97.2 & 87 & 97.8 \\
\hline \multirow[t]{2}{*}{ smoking after you diagnosed hypertension } & Yes & 3 & 0.8 & 0 & 0 \\
\hline & No & 353 & 99.2 & 89 & 100 \\
\hline \multirow[t]{2}{*}{ Regular physical exercise } & yes & 111 & 31.2 & 26 & 29.2 \\
\hline & No & 245 & 68.8 & 63 & 70.8 \\
\hline \multirow[t]{2}{*}{ Medication non-adherence } & Yes & 106 & 29.8 & 59 & 66.3 \\
\hline & No & 250 & 70.2 & 30 & 33.7 \\
\hline \multirow[t]{2}{*}{ Have ever drink alcohol } & Yes & 255 & 71.6 & 67 & 75.3 \\
\hline & No & 101 & 28.4 & 22 & 24.7 \\
\hline \multirow[t]{2}{*}{ Current alcohol drink } & Yes & 49 & 13.8 & 32 & 36 \\
\hline & No & 307 & 86.2 & 57 & 64 \\
\hline \multirow[t]{2}{*}{ Do reduce salt in diet } & Yes & 328 & 92.1 & 67 & 75.3 \\
\hline & No & 28 & 7.9 & 22 & 24.7 \\
\hline \multirow[t]{2}{*}{ Do you eat fatty diet } & Yes & 71 & 19.9 & 27 & 30.3 \\
\hline & No & 285 & 80.1 & 62 & 69.7 \\
\hline \multirow[t]{2}{*}{ Lost to follow-up } & Yes & 46 & 12.9 & 32 & 36 \\
\hline & No & 310 & 87.1 & 57 & 64 \\
\hline \multirow[t]{3}{*}{ Frequency of fellow up } & 1 month & 85 & 23.9 & 21 & 23.6 \\
\hline & 2 month & 215 & 60.4 & 52 & 58.4 \\
\hline & 3month & 56 & 15.7 & 16 & 18 \\
\hline
\end{tabular}

Table 3: Clinical and anthropometric measurements of hypertensive patients who were attending ACSH, Ethiopia $(n=445), 2018$ 
diagnosis (cases and controls)

Variable

\begin{tabular}{|c|c|c|c|c|c|}
\hline \multirow[b]{3}{*}{ Duration of diagnosis HTN } & \multirow{3}{*}{$\begin{array}{l}\text { Controls } \\
\text { Frequency } \\
\text { <4year }\end{array}$} & \multicolumn{4}{|l|}{ Cases } \\
\hline & & \multirow{2}{*}{$\begin{array}{l}\text { Percentage } \\
249\end{array}$} & \multirow{2}{*}{$\begin{array}{l}\text { Frequency } \\
69.9\end{array}$} & \multicolumn{2}{|c|}{ Percentage } \\
\hline & & & & 53 & 59.6 \\
\hline & >=4year & 107 & 30.1 & 36 & 40.4 \\
\hline \multirow[t]{2}{*}{ Cholesterol level } & Normal & 282 & 79.2 & 56 & 62.9 \\
\hline & High level & 74 & 20.8 & 33 & 37.1 \\
\hline \multirow[t]{2}{*}{ Blood glucose level } & Normal & 304 & 85.4 & 75 & 84.3 \\
\hline & High level & 52 & 14.6 & 14 & 15.7 \\
\hline \multirow[t]{3}{*}{ BMI } & $18.5-24.9$ & 288 & 80.9 & 74 & 83.1 \\
\hline & $25-29.9$ & 60 & 16.9 & 13 & 14.6 \\
\hline & $>=30$ & 8 & 2.2 & 2 & 2.2 \\
\hline \multirow[t]{2}{*}{ Systolic BP } & Controlled & 156 & 43.8 & 15 & 16.9 \\
\hline & Uncontrolled & 200 & 56.2 & 74 & 83.1 \\
\hline Diastolic & Controlled & 163 & 45.8 & 18 & 20.2 \\
\hline \multicolumn{6}{|l|}{ BP } \\
\hline & uncontrolled & 193 & 54.2 & 71 & 79.8 \\
\hline \multirow[t]{2}{*}{ Comorbidities } & yes & 67 & 19.5 & 22 & 24.7 \\
\hline & No & 277 & 80.5 & 67 & 75.3 \\
\hline Family history & Yes & 25 & 7 & 5 & 5.6 \\
\hline \multicolumn{6}{|l|}{ of stroke } \\
\hline & No & 331 & 93 & 84 & 94.4 \\
\hline
\end{tabular}

Table 4: Bivariate and multivariable logistic regression for determinant of stroke in ACSH, Ethiopia, 2018 $(\mathrm{n}=445)$ 
Variables

Cases and

Controls $(n=445)$

COR P-value AOR(95\%CI) P-value* $(95 \% \mathrm{CI})$

Cases $\%$

Age category

$<45$ years $\quad 23(25.8 \%)$

45-65 years $\quad 39(43.8 \%)$

$>65$ years

$27(30.3 \%)$

\section{Controls $\%$}

0.006

0.074

$116(32.6 \% \quad 1$

185(52\%)

1.063(0.604- 0.832 1.871)

$55(15.4 \%)$

0.006

2.476(1.303-

4.705)*

1

$.811(.418-$

0.535

1.573)

$1.779(.836-$

3.787)

Lost to follow

up

Yes

No

$32(36 \%)$

$57(64 \%)$
46(12.9\%)

$310(87.1 \%)$
3.783(2.222- $\quad 0.000$ 6.442)*

1
2.597(1.368- 0.004 4.929)*

1

Current

alcohol drink

Yes

No

$32(36 \%)$

$57(64 \%)$
49(13.8\%)

307(86.2\%) $3.517(2.075-\quad 0.000$ 5.961)*

1 $2.440(1.291-\quad 0.006$ 4.613)*

1

Do you reduce salt in diet

Yes

No

67(75.3\%)

$22(24.7 \%)$
328(92.1\%) 1

28(7.9\%)

3.846(2.075- $\quad 0.000$ 7.130)*

1

$3.249(1.544-\quad 0.002$ 6.837)*

Do you eat

fatty foods

Yes

No

$$
27(30.3 \%)
$$

$62(69.7 \%)$
71(19.9\%)

285(80.1\%)
1.748(1.038- 0.036 2.944)*

1
1.388(.733- $\quad 0.314$

2.63)

1

Medication

adherence

No adherent

Adherent

$59(66.3 \%)$

106(29.8\%)

4.638(2.828- $\quad 0.000$
$7.607)^{*}$

3.967(2.2566.973)* 
Cholesterol

level

Normal

High level

$56(62.9 \%)$

$33(37.1 \%)$
$282(79.2 \%) \quad 1$

$74(20.8 \%)$

4.560(2.3138.989)*

0.002

2.413(1.3194.414)*

0.004

Systolic BP

Controlled

$15(16.9 \%)$

156(43.8\%) 1

1

Uncontrolled 74(83.1\%)

200(56.2\%)

3.848(2.126- 0.000

3.196(1.60-

6.382)*

0.001

$0.382) *$

Diastolic BP

\begin{tabular}{|c|c|c|c|c|c|c|}
\hline Controlled & $18(20.2 \%)$ & $163(45.8 \%)$ & 1 & & 1 & \\
\hline Uncontrolled & $71(79.8 \%)$ & 193(54.2\%) & $\begin{array}{l}3.331(1.907- \\
5.818)^{*}\end{array}$ & 0.000 & $\begin{array}{l}2.204(1.130- \\
4.297)\end{array}$ & 0.020 \\
\hline
\end{tabular}

$\mathrm{P}$-value $=\mathrm{p}$-value in bivariate logistic regression, $\mathrm{P}$-value*=p-value in multivariable logistic regression COR: crude odds ratio, AOR: adjusted odds ratio, CI: confidence interval, *: statically significant

\section{ANEX 1}

Table 5: Bivariate and multivariable logistic regression for determinant of stroke in ACSH, Ethiopia, 2018 $(n=445)$ 
Variables

Cases and

Controls $(n=445)$

COR P-value+ AOR(95\%CI) P-value

(95\%CI)

\section{Cases\%}

Sex category

Male

Female

Age category

$<45$ years

45-65 years

$>65$ years
$46(51.7 \%$

$43(48.3 \%)$

$23(25.8 \%)$

$39(43.8 \%)$

$27(30.3 \%)$

$57(64 \%)$

$16(18 \%)$

$6(6.7 \%)$

$10(11.2 \%)$

\section{Controls\%}

$170(47.8 \%) \quad 1$

$186(52.2 \%) \quad .854(.537-\quad 0.507$ 1.360)

0.006

0.074

$116(32.6 \% \quad 1$

185(52\%)

1.063(0.604- 0.832

1.871)

$55(15.4 \%)$

$2.476(1.303-$

4.705)*

0.006

.573)

$1.779(.836$

3.787)

Marital status

0.934

Married

$235(66 \%)$

1

Single

$64(18 \%)$

1.031(0.555-

0.924

Divorced

$25(7 \%)$

1.915)

Widowed

$32(9 \%)$

$0.989(0.388-$

2.525) $\quad 0.517$

$1.288(0.598-$

2.774)

Educational

0.266

status

No formal

education

Primary school

31(34.8\%)

138(38.8\%)

1.084(0.565-

0.809

2.079)

\begin{tabular}{|c|c|c|c|c|}
\hline High school & $25(29.2 \%)$ & $65(18.3 \%)$ & & 0.063 \\
\hline Diploma & $9(10.1 \%)$ & $42(11.8 \%)$ & $\begin{array}{l}1.929(0.965- \\
3.857)\end{array}$ & 0.942 \\
\hline \multirow[t]{2}{*}{$\begin{array}{l}\text { University and } \\
\text { above }\end{array}$} & & $29(8.1 \%)$ & $\begin{array}{l}1.034(0.425- \\
2.516)\end{array}$ & 0.997 \\
\hline & 17(19.1\%) & $82(23 \%)$ & $\begin{array}{l}0.998(0.359- \\
2.775)\end{array}$ & \\
\hline
\end{tabular}




$\begin{array}{lllll}\text { Farmer } & 15(16.9 \%) & 73(20.5 \%) & 1 & \\ \text { House wife } & 5(5.6 \%) & 27(7.6 \%) & \begin{array}{l}0.901(0.299- \\ 2.719)\end{array} & 0.854 \\ \begin{array}{l}\text { Governmental } \\ \text { employee }\end{array} & 20(22.5 \%) & 100(28.1 \%) & 0.942 \\ \text { Non- } & & & 0.973(0.467- & \\ \text { governmental } & 15(16.9 \%) & 32(9 \%) & & 0.051 \\ \text { employee } & & & 2.281(0.997- & \\ \text { Self-employee } & & & 5.219) & \\ \text { Other } & & & & 0.527 \\ & 30(33.7 \%) & 117(32.9 \%) & & 0.137 \\ & 4(4.5 \%) & 7(2 \%) & 1.248(0.629- & \\ & & & 2.476) & \\ & & & 10.709) & \end{array}$

Residency

$\begin{array}{lllll}\text { Rural } & 21(23.6 \%) & 85(23.9 \%) & 0.985(0.570- & 0.956 \\ & & & 1.701) & \\ \text { Urban } & 68(76.4 \%) & 271(76.1 \%) & & \end{array}$

Family history

of stroke

Yes

No

$5(5.6 \%)$

$84(94.4 \%)$
$25(7 \%)$

331(93\%)
Clinical duration of hypertension

$<4$ years

$>=4$ years
$53(59.6 \%)$

$36(40.4 \%)$
$249(69.9 \%) \quad 1$

$107(30.1 \%) \quad 1.581(0.978-\quad 0.062$
$.788(.293-$

2.120)

1

1

0.637

Frequency of

fellow up

Every 1month

Every 2month

$21(23.6 \%) \quad 85(23.9 \%) \quad 1$




$\begin{array}{lllll}\text { Every 3month } & 52(58.4 \%) & 215(60.4 \%) & 0.979(0.556- & 0.941 \\ & & & 1.723) & 0.697 \\ & 16(18 \%) & 56(15.7 \%) & & 1.156(0.556- \\ & & & \\ & & & \\ & & & \end{array}$

Have you ever lost to follow up

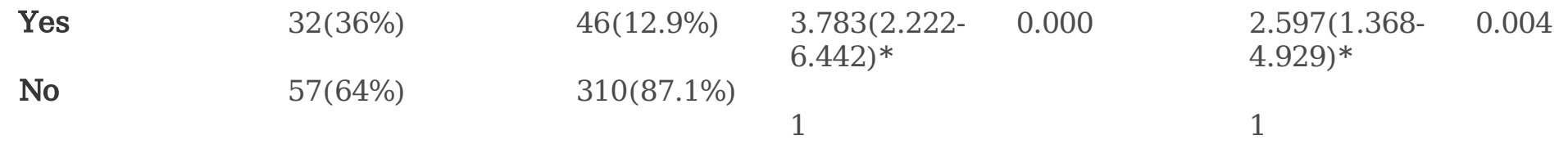

Ever alcohol drink

Yes

No

$$
\text { 67(75.3\%) }
$$

$22(24.7 \%)$

$255(71.6 \%)$

1.206(.707-

2.057)

101(28.4)

1
Have you drink alcohol after you diagnosed

\section{Yes}

No

$32(36 \%)$

$57(64 \%)$
$49(13.8 \%)$

307(86.2\%)
3.517(2.075- $\quad 0.000$ 5.961)*

1 $2.440(1.291-\quad 0.006$ 4.613)*

1

Do you reduce salt in diet

Yes

No

67(75.3\%)

$22(24.7 \%)$
328(92.1\%)

$28(7.9 \%)$
1

3.846(2.075- $\quad 0.000$ 7.130)*
1

$3.249(1.544-\quad 0.002$ 6.837)*

Do you eat fatty foods

Yes

No

27(30.3\%)

$62(69.7 \%)$
71(19.9\%)

$285(80.1 \%)$ $1.748(1.038-\quad 0.036$ 2.944)*

1
1.388(.733-

2.63)

1

Regular exercise

Active

Inactive

$26(29.2 \%)$

$63(70.8 \%)$
111(31.2\%) 1

245(68.8\%
0.719 
Comorbidities

$\begin{array}{lllll}\text { Yes } & 22(24.7 \%) & 67(19.5 \%) & 1.358(0.783- & 0.277 \\ \text { No } & 67(75.3 \%) & 277(80.5) & 2.354) & \\ & & & 1\end{array}$

Medication

adherence

No adherent

$59(66.3 \%)$

106(29.8\%)

4.638(2.828- $\quad 0.000$

3.967(2.256- 0.000

Adherent

$30(33.7 \%)$ 7.607)*

6.973)*

$250(70.2 \%)$

1

1

Fasting blood

sugar level

Normal

High level

75(84.3\%)

304(85.4\%) 1

$14(15.7 \%)$

$52(14.6 \%)$

1.091(0.574-

0.790

2.074)

BMI

Normal weight

$74(83.1 \%)$

288(80.9\%) 1

Over weight

13(14.6\%)

Obesity

$2(2.2 \%)$

$60(16.9 \%)$

$0.843(0.439-$

1.618)

$8(2.2 \%)$

0.973(0.202-

4.679)

Cholesterol

level

Normal

High level

$56(62.9 \%)$

33(37.1\%)
$282(79.2 \%) \quad 1$

$74(20.8 \%)$

4.560(2.313 8.989)*
0.608

0.973

0.877

(


Controlled

\begin{tabular}{|c|c|c|c|c|c|c|}
\hline Uncontrolled & $18(20.2 \%)$ & $163(45.8 \%)$ & 1 & & 1 & \\
\hline & $71(79.8 \%)$ & $193(54.2 \%)$ & $\begin{array}{l}3.331(1.907- \\
5.818)^{*}\end{array}$ & 0.000 & $\begin{array}{l}2.204(1.130- \\
4.297)\end{array}$ & 0.020 \\
\hline
\end{tabular}

$\mathrm{P}$-value $+=\mathrm{p}$-value in bivariate logistic regression, $\mathrm{P}$-value $++=\mathrm{p}$-value in multivariable logistic regression COR: crude odds ratio, AOR: adjusted odds ratio, CI: confidence interval,*: statically significance

\section{Supplementary Files}

This is a list of supplementary files associated with this preprint. Click to download.

- Englishversionquestioneer.docx 